Review

\title{
Chitosan derivatives obtained by chemical modifications for biomedical and environmental applications
}

\author{
N.M. Alves ${ }^{\mathrm{a}, \mathrm{b}, *}$, J.F. Mano ${ }^{\mathrm{a}, \mathrm{b}}$ \\ a 3B's Research Group - Biomaterials, Biodegradables and Biomimetics, Dept. of Polymer Engineering, University of Minho, Headquarters of the European Institute of Excellence \\ on Tissue Engineering and Regenerative Medicine, AvePark, Zona Industrial da Gandra, S. Cláudio do Barco, 4806-909 Caldas das Taipas, Guimarães, Portugal \\ ${ }^{\mathrm{b}}$ IBB-Institute for Biotechnology and Bioengineering, Braga, Portugal
}

\section{A R T I C L E I N F O}

\section{Article history:}

Received 12 August 2008

Received in revised form 5 September 2008

Accepted 8 September 2008

Available online 16 September 2008

\section{Keywords:}

Chitosan

Chitosan derivatives

Biomedical applications

Biomaterials

Polysaccharides

\begin{abstract}
A B S T R A C T
Chitosan is a natural based polymer, obtained by alkaline deacetylation of chitin, which presents excellent biological properties such as biodegradability and immunological, antibacterial and wound-healing activity. Recently, there has been a growing interest in the chemical modification of chitosan in order to improve its solubility and widen its applications. The main chemical modifications of chitosan that have been proposed in the literature are reviewed in this paper. Moreover, these chemical modifications lead to a wide range of derivatives with a broad range of applications. Recent and relevant examples of the distinct applications, with particular emphasis on tissue engineering, drug delivery and environmental applications, are presented.
\end{abstract}

(c) 2008 Elsevier B.V. All rights reserved.

\section{Contents}

1. Introduction

2. Graft copolymerization ....

2.1. Grafting initiated by free radicals

2.2. Grafting using radiation .....

2.3. Enzymatic grafting

2.4. Cationic graft polymerization

3. Special cases of chitin and chitosan modifications

3.1. Phosphorylated chitin and chitosan...

3.2. Combination of chitosan derivatives with cyclodextrins .

3.3. Thiol-containing chitosan....

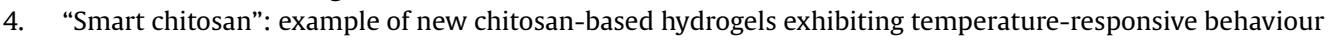

4.1. Graft copolymerized hydrogels ...

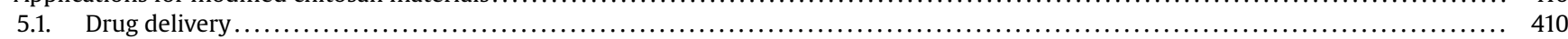

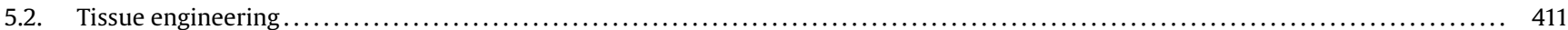

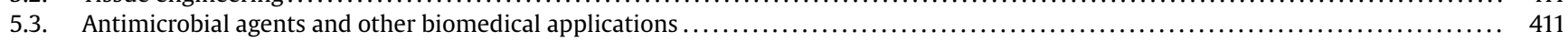

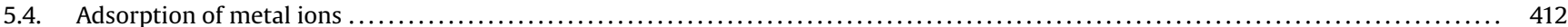

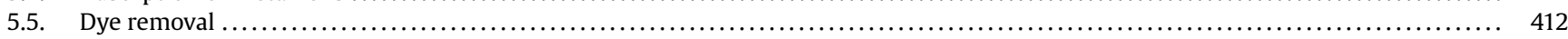

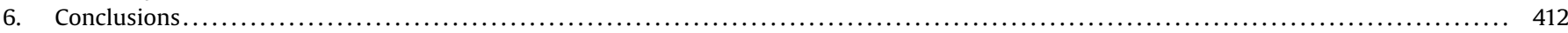

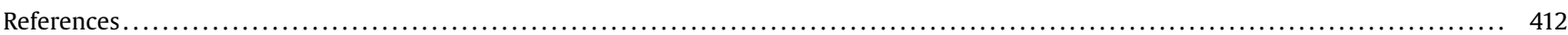

\footnotetext{
* Corresponding author at: 3B's Research Group - Biomaterials, Biodegradables and Biomimetics, Dept. of Polymer Engineering, University of Minho, Headquarters of the European Institute of Excellence on Tissue Engineering and Regenerative Medicine, AvePark, Zona Industrial da Gandra, S. Cláudio do Barco, 4806-909 Caldas das Taipas, Guimarães, Portugal.

E-mail address: nalves@dep.uminho.pt (N.M. Alves).
} 


\section{Introduction}

Chitosan is typically obtained by deacetylation of chitin under alkaline conditions, which is one of the most abundant organic materials, being second only to cellulose in the amount produced annually by biosynthesis. Chitin is an important constituent of the exoskeleton in animals, especially in crustaceans, molluscs and insects. It is also the principal fibrillar polymer in the cell wall of certain fungi. As shown in Fig. 1, chitosan is a linear polysaccharide, composed of glucosamine and $N$-acetyl glucosamine units linked by $\beta(1-4)$ glycosidic bonds. The content of glucosamine is called the degree of deacetylation (DD). In fact, in a general way, it is considered that when the DD of chitin is higher than about $50 \%$ (depending on the origin of the polymer and on the distribution of acetyl groups along the chains), it becomes soluble in an aqueous acidic medium, and in these conditions, it is named chitosan. The DD also affects the biodegradability of this polymer, and for DD above 69\% a significant decrease in in vivo degradation has been found [1]. In fact, for fully deacetylated chitosan, no susceptibility to lysozyme has been observed [1,2].

Chitosan displays interesting properties such as biocompatibility, biodegradability [3,4] and its degradation products are non-toxic, non-immunogenic and non-carcinogenic [5,6]. Therefore, chitosan has prospective applications in many fields such as biomedicine, waste water treatment, functional membranes and flocculation. However, chitosan is only soluble in few dilute acid solutions, which limits its applications.

Recently, there has been a growing interest in the chemical modification of chitosan in order to improve its solubility and widen its applications [7-9]. Derivatization by introducing small functional groups to the chitosan structure, such as alkyl or carboxymethyl groups $[10,11]$ can drastically increase the solubility of chitosan at neutral and alkaline $\mathrm{pH}$ values without affecting its cationic character. Substitution with moieties bearing carboxylic groups can yield polymers with polyampholytic properties [12]. Among the various methods of modification, graft copolymerization has been the most used. Grafting of chitosan allows the formation of functional derivatives by covalent binding of a molecule, the graft, onto the chitosan backbone. Chitosan has two types of reactive groups that can be grafted. First, the free amine groups on deacetylated units and secondly, the hydroxyl groups on the $C_{3}$ and $C_{6}$ carbons on acetylated or deacetylated units. Recently researchers have shown that after primary derivation followed by graft modification, chitosan would obtain much improved water solubility, antibacterial and antioxidant properties $[13,14]$. Grafting chitosan is also a common way to improve other properties such as increasing chelating [15] or complexation properties [16], bacteriostatic effect [17] or enhancing adsorption properties [18]. Although the grafting of chitosan modifies its properties, it is possible to maintain some interesting characteristics such as mucoadhesivity [19], biocompatibility [20,21] and biodegradability [22].

The main methods that have been used to chemically modify chitosan will be described in this paper. Some representative examples of the chemical reactions and experimental conditions used will be presented. Finally the most important applications of such modified chitosan-based materials in different fields are also discussed.

\section{Graft copolymerization}

As said before, graft copolymerization is the main method used to modify chitosan chemically. In recent years, a number of initiator systems such as ammonium persulfate (APS), potassium persulfate (PPS), ceric ammonium nitrate (CAN), thiocarbonationpotassium bromate (TCPB), potassium diperiodatocuprate (III) (PDC), 2,2'azobisisobutyronitrile (AIBN) and ferrous ammonium sulfate (FAS) have been developed to initiate grafting copolymerization [23-26]. Graft copolymerization can also be initiated by $\gamma$-irradiation and enzymes. The grafting parameters such as grafting percentage and grafting efficiency are greatly influenced by several parameters such as the type and concentration of initiator, monomer concentration, reaction temperature and time. The properties of the resulting graft copolymers are widely controlled by the characteristics of the side chains, including molecular structure, length, and number. Until now, many researchers have studied the effects of these variables on the grafting parameters and the properties of the resultant grafted chitosan (e.g., Refs. [14,23-26]). Some representative examples of the previously mentioned methods used for grafting chitosan will now be described separately.

\subsection{Grafting initiated by free radicals}

Graft copolymerization of vinyl monomers onto chitosan using free radical initiation has attracted the interest of many scientists in the last two decades. For example, Sun et al. prepared carboxymethyl chitosan-grafted methacrylic acid (MAA) by using APS as an initiator in aqueous solution [27]. The effects of APS, MAA, reaction temperature and time on graft copolymerization were analysed by determining the grafting percentage and grafting efficiency. After grafting, the chitosan derivatives had much improved water solubility. Similarly, Xie et al. prepared hydroxypropyl chitosan-grafted MAA by using APS initiator (Fig. 2) [14], obtaining a derivative that also presented a good solubility in water.

The graft copolymerization of maleic acid sodium (MAS) onto carboxymethyl chitosan and hydroxypropyl chitosan using APS initiator was reported [28]. The antioxidant activity of these derivatives was evaluated as superoxide anion scavengers by chemiluminescence technology. Compared with chitosan, the graft chitosan derivatives were found to have an improved scavenging ability against superoxide anion. Graft chitosan derivatives with hydroxypropyl groups had relatively higher superoxide anion scavenging ability owing to the incorporation of hydroxyl groups. Acylation of chitosan with maleic anhydride furnishes carbon-carbon double bonds, which are available for subsequent polymerization. The copolymerization of the derivative with acrylamide in water in the presence of APS has been used to obtain three-dimensional crosslinked products [29]. The resulting copolymers swelled highly in water with a volume increase of 20-150 times. Poly(3-hydroxy-butylate) could also be introduced into chitosan by $\mathrm{N}$-acylation, and the resulting copolymer was found to be partially soluble in water [30].

Graft copolymerization of vinyl monomers onto chitosan can also be carried out using redox initiator systems, such as CAN and PPS. These systems have been used to produce free radical sites on many kinds of polymers. Poly(vinyl acetate) (PVAc) is known as a leathery and water-resistant polymer, which may improve the properties of chitosan material and hence the graft polymerization of vinyl acetate onto chitosan by using CAN as an initiator was reported [23]. The monomer conversion was found to be between 70 and $80 \%$ after $2 \mathrm{~h}$ of reaction at $60^{\circ} \mathrm{C}$. The grafting efficiency increased with increasing amount of chitosan. The experimental results indicated that the chitosan molecules not only took part in the graft copolymerization but also act as a surfactant, providing the stability of the dispersed particles. The data also showed that the incorporation of PVAc to the chitosan chains increased the toughness and decreased the water absorption of chitosan.

CAN was also found to be a suitable initiator for grafting $\mathrm{N}, \mathrm{N}$-dimethyl- $\mathrm{N}$-methacryloxyethyl- $\mathrm{N}$-(3-sulfopropyl) ammonium 


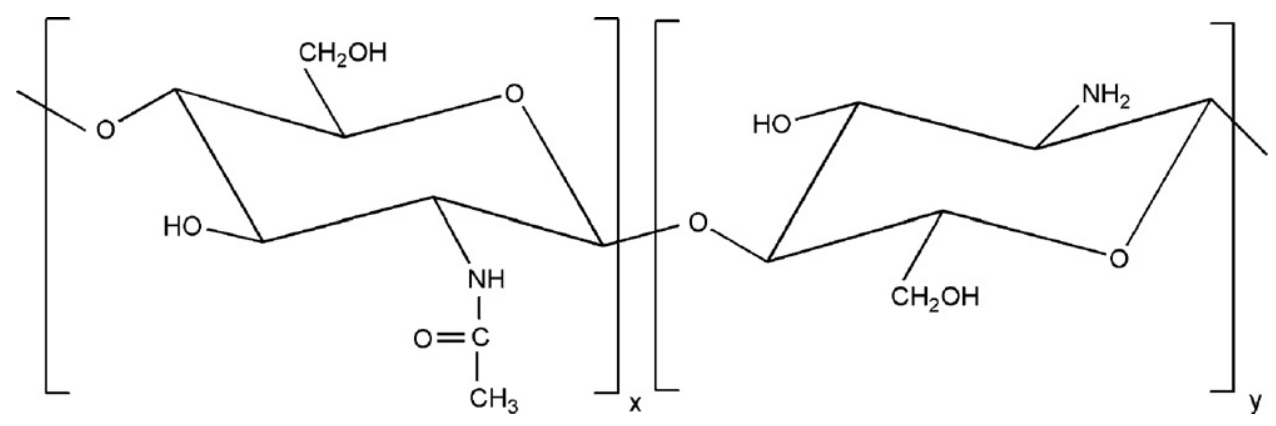

Fig. 1. Chemical structure of chitosan.

[31], poly(acrylonitrile) (PAN) [32], polyacrylamide, poly(acrylic acid) and poly(4-vinylpyridine) [33] onto chitosan.

Chitosan was modified with poly(acrylic acid), a well known hydrogel forming polymer, using a grafting reaction in a homogeneous phase [25]. The grafting was carried out in presence of PPS and FAS as the combined redox initiator system. It was observed that the level of grafting could be controlled to some extent by varying the amount of ferrous ion as a co-catalyst in the reaction. The maximum efficiency of grafting attained in this work (52\%) is rather high but it is comparable with values reported recently in the literature for the grafting of vinyl monomers onto polysaccharides. This result revealed that in homogeneous systems the grafting reactions takes place not only on the surface but also in the molecules of the whole substrate. Tahlawy and Hudson [34] have discussed the effects of the reaction conditions and temperature on the grafting efficiency of 2-hydroxyethyl methacrylate (HEMA) onto chitosan in presence of redox initiators, in this case TCPB. Here, the total conversion of HEMA monomer was found to be up to $75 \%$. The resulting material was found to increase the hydrophilicity and therefore may be used as textile finishes enhancing the hydrophilicity of synthetic fibers.

A novel redox system, PDC [Cu (III)-chitosan], was employed to initiate the graft copolymerization of methyl acrylate onto chitosan in alkali aqueous solution [35]. In this work, Cu (III) was employed as an oxidant and chitosan as a reductant in the redox system used to initiate the grafting reaction. The result showed that there is a high grafting efficiency and percentage when using PDC as an initiator. Since the activation energy of the reaction employing $\mathrm{Cu}$ (III)-chitosan as an initiator is low, the graft copolymerization is carried out at a mild temperature of $35^{\circ} \mathrm{C}$ and in alkali aqueous medium, which makes it superior to other initiators. Graft copolymerization onto chitosan has also been attempted by using AIBN. Some vinyl monomers such as acrylonitrile, methyl methacrylate, methyl acrylate, and vinyl acetate were grafted onto chitosan with AIBN in aqueous acetic acid solutions or in aqueous suspensions [26]. Here, the grafting percentages were generally low [26]. Fenton's reagent $\left(\mathrm{Fe}^{2+} / \mathrm{H}_{2} \mathrm{O}_{2}\right)$ was also successfully used as a redox initiator for grafting methyl methacrylate onto chitosan [36]. Although chitosan is an effective flocculating agent only in acidic media, the derivatives having side chain carboxyl groups showed zwitterionic characteristics with high flocculation abilities in both acidic and basic media.

\subsection{Grafting using radiation}

Recently, a great interest has been made to graft natural polymers using the radiation method. Grafting of polystyrene onto chitin and chitosan using ${ }^{60} \mathrm{Co} \gamma$-irradiation at room temperature was investigated $[37,38]$. The effect of various conditions such as adsorbed dose, solvent and oxygen on grafting was analysed. It was found that the grafting yield increased with the increase in the adsorbed dose. Singh and Roy have also reported radiation grafting of chitosan with $N, N^{\prime}$-dimethylaminoethylmethacrylate (DMAEMA) [39]. Parameters such as solvent composition, monomer concentration, radiation dose rate, and total dose/time were found to affect the rate of grafting and homopolymerization. In this study, it was found that a desired level of grafting of DMAEMA onto chitosan films was achieved by appropriate selection of these grafting conditions. Yu et al. have reported the graft copolymerization of butyl acrylate onto chitosan by using $\gamma$-irradiation [40]. In this study, an increasing grafting percentage was observed when the monomer concentration and total dose were increased or when the chitosan concentration and reaction temperature were decreased. Under lower dose rates, the grafting percentage had no significant changes, whereas above $35 \mathrm{~Gy} / \mathrm{min}$ (dose rate) exhibited a sharp decrease. Compared with the pure chitosan film, the

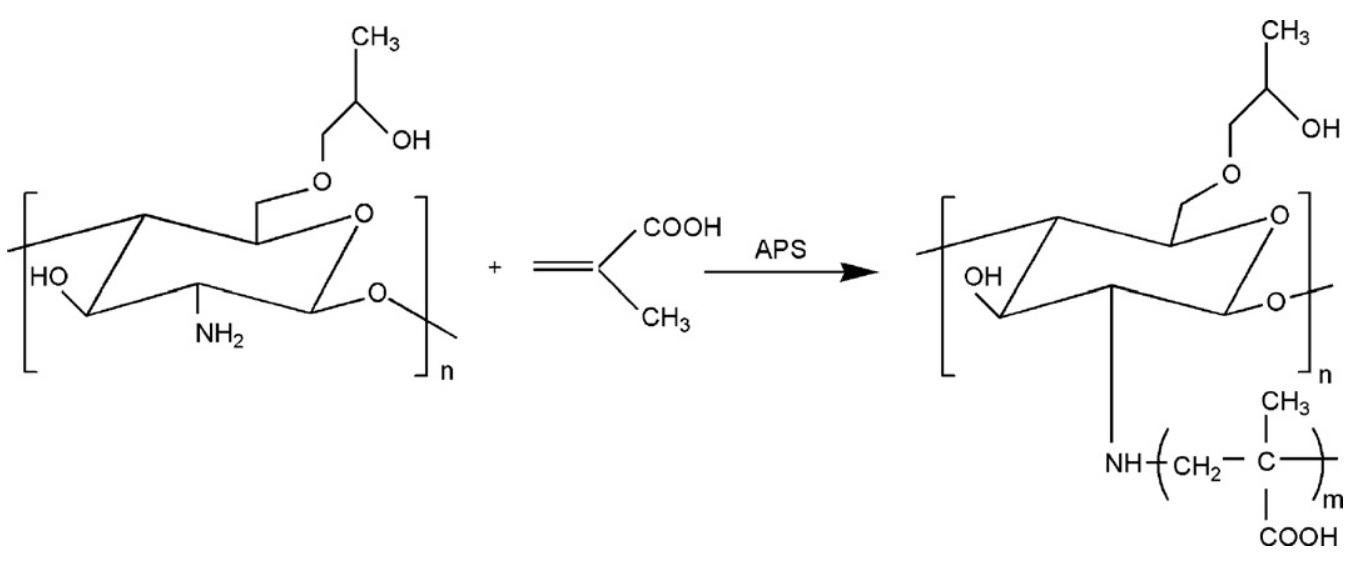

Fig. 2. Graft copolymerization of MAA on hydroxypropyl chitosan. 
<smiles>[R]c1ccc(O)cc1</smiles>

Phenol<smiles>C[C@H](O)[C@@H](O)C#N</smiles><smiles>[R]C1=CC(=O)C(=O)C=C1</smiles>

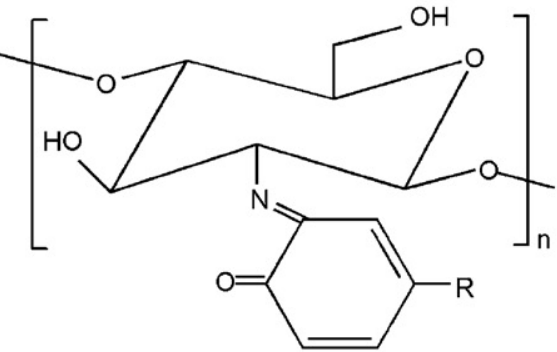

Schiff base

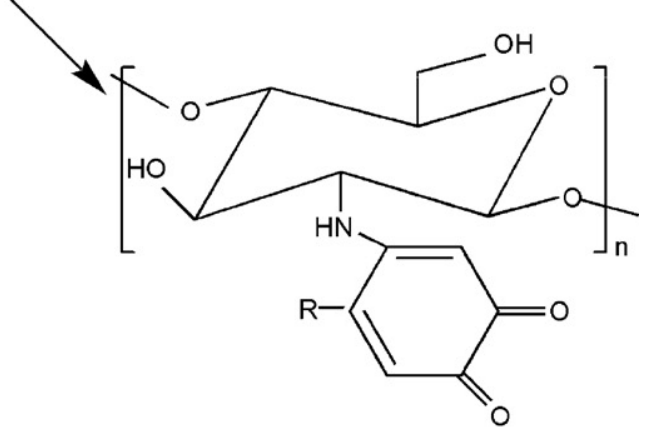

Michael's-type adduct<smiles>O=C(/C=C/c1ccc(O)c(O)c1)OCCOC(=O)OCc1ccc(O)c(O)c1</smiles>

Hexyloxy phenol<smiles>COc1ccc(O)cc1</smiles>

Hexyloxy phenol

Fig. 3. Enzymatic grafting of chitosan with phenol and tyrosinase.

chitosan graft poly(butyl acrylate) films have enhanced hydrophobicity and impact strength.

The grafting of poly(hydroxyethyl methacrylate) onto chitosan has been reported but in this case by applying UV light [41]. Here, the sulfite oxidase enzyme was covalently immobilized onto the matrix of grafted polymer. After the completion of photo-induced polymerization reaction, P-benzoquinone (an electron transfer mediator) was coupled onto the polymer network for activation of the chitosan-poly(hydroxyethyl methacrylate) copolymer. This study demonstrated the feasibility of using chitosan in electrochemical biosensor fabrication [41].

Singh et al. grafted poly(acrylonitrile) onto chitosan using the microwave irradiation technique under homogeneous conditions [42]. They have obtained 70\% grafting yield within $1.5 \mathrm{~min}$. The effects of reaction variables as monomer and chitosan con- centration, microwave power, and exposure time on the graft copolymerization were studied. The grafting was found to increase with an increase in the monomer concentration. Grafting was also found to increase up to $80 \%$ microwave power and thereafter decreased.

\subsection{Enzymatic grafting}

There are several potential advantages for the use of enzymes in polymer synthesis and modification $[43,44]$. With respect to health and safety, enzymes offer the potential of eliminating the hazards associated with reactive reagents. A potential environmental benefit for using enzymes is that their selectivity may be exploited to eliminate the need for waste full protection and deprotection steps. Finally, enzymes specificity may offer the potential 


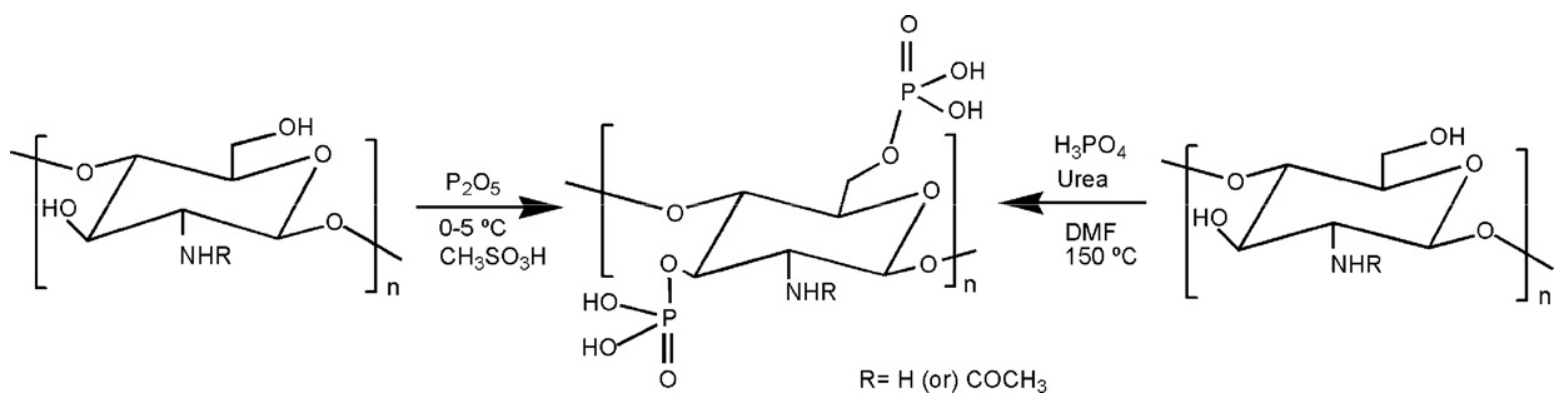

Fig. 4. Synthesis of phosphorylated chitin and chitosan.

for precisely modifying macromolecular structure to better control polymer function $[45,46]$. For instance, enzymatic modification can yield chitosan derivatives with unique $\mathrm{pH}$-sensitive water solubility and adhesive properties.

Kumar et al. [45] reported that enzymatic grafting of phenolic compounds onto chitosan confer water solubility under basic conditions (Fig. 3). Tyrosinase converts a wide range of phenolic substrates into electrophilic o-quinones. In slightly acidic media ( $\mathrm{pH}$ 6), chitosan could be modified under homogeneous conditions with the natural product chlorogenic acid. The modified chitosan was soluble under both acid and basic conditions, even when the degree of modification was low. The chemistry of quinones, however, remains poorly characterized because of its complexity; quinones can undergo two different reactions to yield either Schiff bases or Michael type adducts. Since it is possible for quinones to undergo either or both type of reactions with amines, as well as oligomer forming reactions with other quinones, it is common for reactions between quinones and amines to yield complex mixtures of products.

The feasibility of using tyrosinase as a catalyst for grafting hexyloxyphenol onto the chitosan was also investigated [47]. The method employed tyrosinase to convert the phenol into a reactive $o$-quinone, which undergoes subsequent non-enzymatic reaction with chitosan under homogeneous conditions (Fig. 3). From the biochemically relevant quinones studied so far, it would seem possible to prepare materials of medical interest. For instance, menadione, a synthetic naphthoquinone derivative having the physiological properties of vitamin $\mathrm{K}$ is particularly prone to rapid reaction with chitosan, greatly modifying its spectral characteristics and increasing the surface hydrophobicity of treated chitosan films [48].

\subsection{Cationic graft polymerization}

Some years ago, Yoshikawa et al. showed that grafting reactions onto chitosan can also be performed by using living cationic polymerization [49]. These authors grafted chitosan with living poly(isobutylvinyl ether) and poly(2-methyl-2-oxazoline) cation with controlled molecular weight distribution. In this study, the effect of molecular weight of living polymer cation on the mole number of grafted polymer was analysed. The mole number of grafted polymer chains was found to decrease with increasing molecular weight of living polymer cation, due to the steric hindrance of the functional groups of chitosan with increasing molecular weight of living polymer. The viscosity of the resulting polymer was found to increase with the increasing percentage of grafting. This grafted polymer was also found to be soluble in water.

\section{Special cases of chitin and chitosan modifications}

Besides graft copolymerization and derivatization by introducing small functional groups to the chitosan structure, some other chemical modifications of chitosan and chitin deserve to be included in this chapter due to the potential applications of such chitosan derivatives. These chemical modifications are: phosphorylation of chitosan and chitin, combination of chitosan derivatives with cyclodextrins and thiolation of chitosan.

\subsection{Phosphorylated chitin and chitosan}

The reaction of chitin with phosphorous pentoxide was found to give water-soluble phosphorylated chitin of high degree of substitution (DS), constituting a strategy to overcome this major drawback of chitin and its derivatives. Phosphorylated chitin (Pchitin) and chitosan (P-chitosan) were prepared by heating chitin or chitosan with orthophosphoric acid and urea in DMF [50-52] (Fig. 4).

P-chitin and P-chitosan were also prepared by the reaction of chitin or chitosan with phosphorous pentoxide in methane sulphonic acid $[53,54]$. The phosphorylation reactions of chitin and chitosan in phosphorous pentoxide-methane sulphonic acid were found to be very efficient [55-58]. However, in this case it was found that only the P-chitosan with low DS was water soluble. The incorporation of methylene phosphonic groups into chitosan allowed solubility in water under neutral conditions [59]. A water-soluble $\mathrm{N}$-methylene phosphonic chitosan (NMPC) was also synthesized using chitosan, phosphorous acid and formaldehyde [59].

$$
[-\mathrm{A}-/-\mathrm{B}-/-\mathrm{C}-/-\mathrm{D}-/-\mathrm{E}-/ \ldots]_{\mathrm{n}}
$$

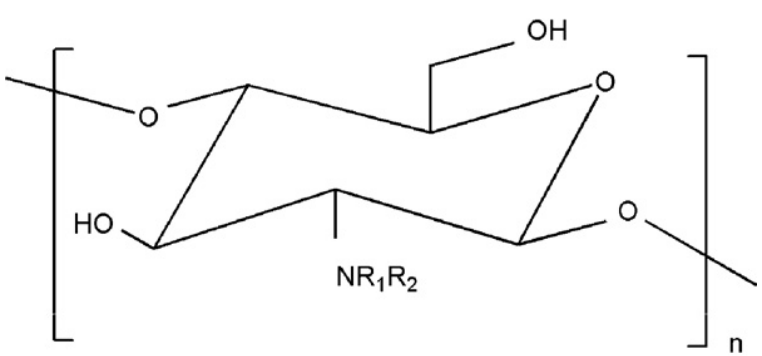

\begin{tabular}{|l|l|l|}
\hline & \multicolumn{1}{|c|}{$\mathrm{R}_{1}$} & \multicolumn{1}{c|}{$\mathrm{R}_{2}$} \\
\hline$A$ & $-\mathrm{H}$ & $-\mathrm{COCH}_{3}$ \\
\hline$B$ & $-\mathrm{H}$ & $-\mathrm{H}$ \\
\hline$C$ & $-\mathrm{H}$ & $-\mathrm{CH}_{2}-\mathrm{PO}_{3} \mathrm{H}_{2}$ \\
\hline$D$ & $-\mathrm{CH}_{2}-\mathrm{PO}_{3} \mathrm{H}_{2}$ & $-\mathrm{CH}_{2}-\mathrm{PO}_{3} \mathrm{H}_{2}$ \\
\hline$E$ & $-\mathrm{H}$ & $-\left(\mathrm{CH}_{2}\right)_{11}-\mathrm{CH}_{3}$ \\
\hline
\end{tabular}

Fig. 5. Chemical structure of $N$-lauryl- $N$-methylene phosphonic chitosan (LMPC). 


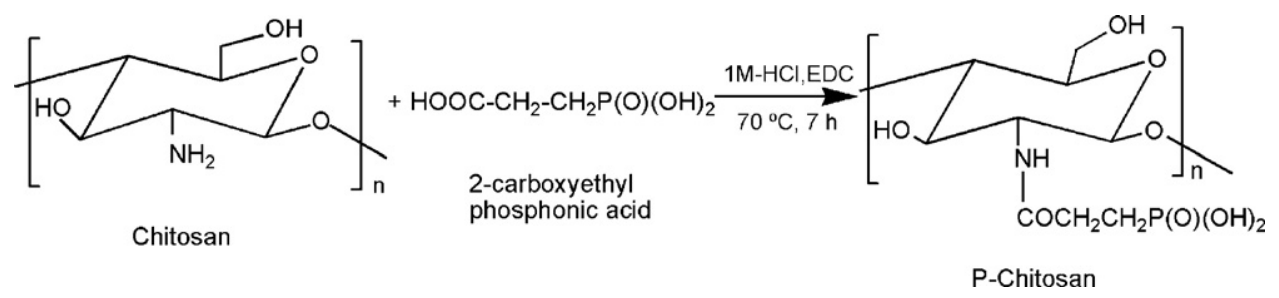

Fig. 6. Synthesis of P-chitosan by grafting.

A simple methodology for the preparation of a new chitosan derivative surfactant, $N$-lauryl- $N$-methylene phosphonic chitosan (LMPC), has been developed [60] (Fig. 5). LMPC incorporated $N$ methylene phosphonic groups as hydrophilic moieties and lauryl groups as the hydrophobic ones.

$\mathrm{N}$-Phosphonomethylation of chitosan reaction was studied and optimized using different reaction conditions [61]. The reaction was conducted with a large excess of both phosphorous acid and formaldehyde at $70^{\circ} \mathrm{C}$. The obtained white solid was found to be soluble in neutral and acidic aqueous solutions.

Ramos et al. [62] prepared $N$-methylene phosphonic and carboxylic chitosan (NMPCC) by using NMPC and glyoxallic acid (via aldimine formation) under reduction conditions with sodium borohydride. This new chitosan multidentate ligand presents both carboxylic and phosphonic groups [62].

P-chitosan was also synthesized by graft copolymerization [63]. 2-Carboxethylphosphonic acid was covalently attached onto chitosan by using 1-ethyl-3-(3-dimethylaminopropyl) carbodiimide (EDC) mediated coupling reaction (Fig. 6).

\subsection{Combination of chitosan derivatives with cyclodextrins}

Cyclodextrins (CDs) are cyclic oligosaccharides built from six to eight $(\alpha=6, \beta=7, \gamma=8)$ D-glucose units and are formed during the enzymatic degradation of starch and related compounds [64]. The D-glucose units are covalently linked together by 1,4 linkages to form torus-like structures (Fig. 7). All the secondary hydroxyl groups at the 2- and 3-positions of the glucose units are on one side of the torus, and all the primary hydroxyl groups at the 6positions of the glucose units are on the other side of the ring [65]. CDs have gained prominence in recent years because their cavity, which is hydrophobic in nature, is capable of binding aromatic and other small organic molecules, and therefore provides ideal binding sites $[66,67]$. Selective functionalization at the 6-position is relatively easy. However, the secondary side is shown to be the more important side of CD in binding studies $[68,69]$. The stability of the CD-inclusion complex depends on the polarity of the guest molecule and on the compatibility of the size of the host and that of the guest [70].

Grafting CD molecules into chitosan-reactive sites may lead to a molecular carrier that possess the cumulative effects of inclusion, size specificity and transport properties of CDs as well as the controlled release ability of the polymeric matrix [71]. The different methods used to graft CD to chitosan and the inclusion ability, sorption and controlled release properties of the products have been reviewed recently [72]. Grafting of CD onto chitosan has been performed by adopting distinct strategies. A possible way is to react EDC with the carboxyl group of carboxymethylated $\beta-C D$ to form an active ester intermediate. The intermediate can react with a primary amine of chitosan to form an amide linkage. Furusaki et al. described the preparation of a $\beta$-CD-grafted chitosan by coupling carboxymethylated $\beta-C D$ and a partially deacetylated chitin oligomer using water-soluble EDC [73].

1,6-Hexamethylene diisocyanate (HMDI), a strong crosslinker of amino or hydroxyl groups since it possesses two isocyanate groups $(-\mathrm{NaCaO})$ has also been used [72]. It is assumed that the crosslinking of the hydroxyl groups of chitosan with HMDI resulted in a chitosan-HMDI complex, which then binds with the hydroxyl groups of $\beta$-CD to form $\beta$-CD-g-chitosan.

Reductive amination, one of the major reactions applicable to the modification of chitosan, has been successfully applied to introduce a $C D$ residue into chitosan. $C D$ derivatives with aldehyde functional groups are useful to graft $C D$ into chitosan by the formation of a Schiff's base. Tanida et al. reported the synthesis of $\beta$-CD-grafted chitosan by the formation of a Schiff's base between 2 - $O$-formylmethyl- $\beta-\mathrm{CD}$ and chitosan in acetate buffer at $\mathrm{pH} 4.4$, followed by reduction with sodium cyanoborohydride [74]. The product, which had a degree of substitution of $37 \%$, was found to be soluble in water at neutral and alkaline conditions. Porous beads having an ability to form inclusion complexes with specific sub-

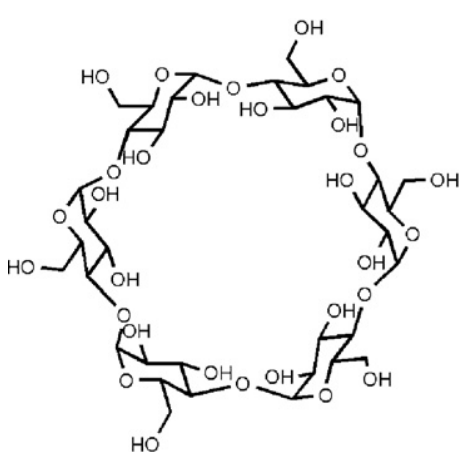

$\alpha-C D$

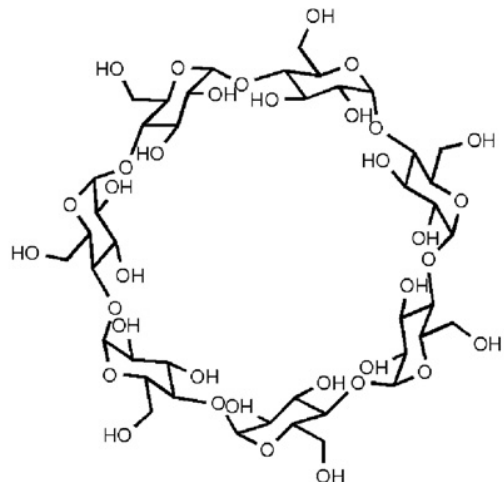

$\beta-C D$

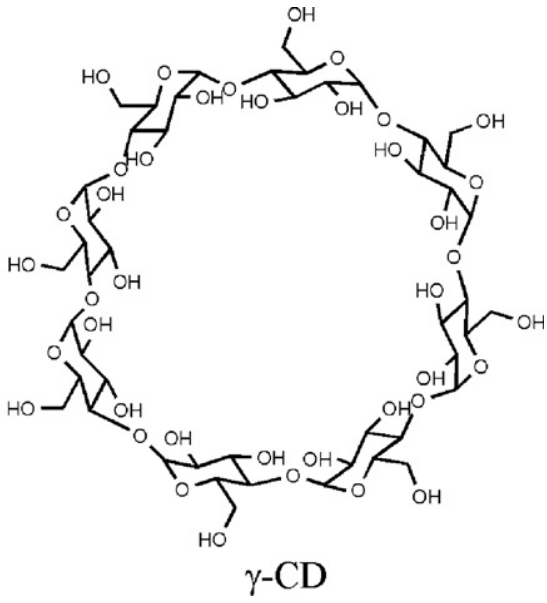

Fig. 7. Chemical structure of CDs. 


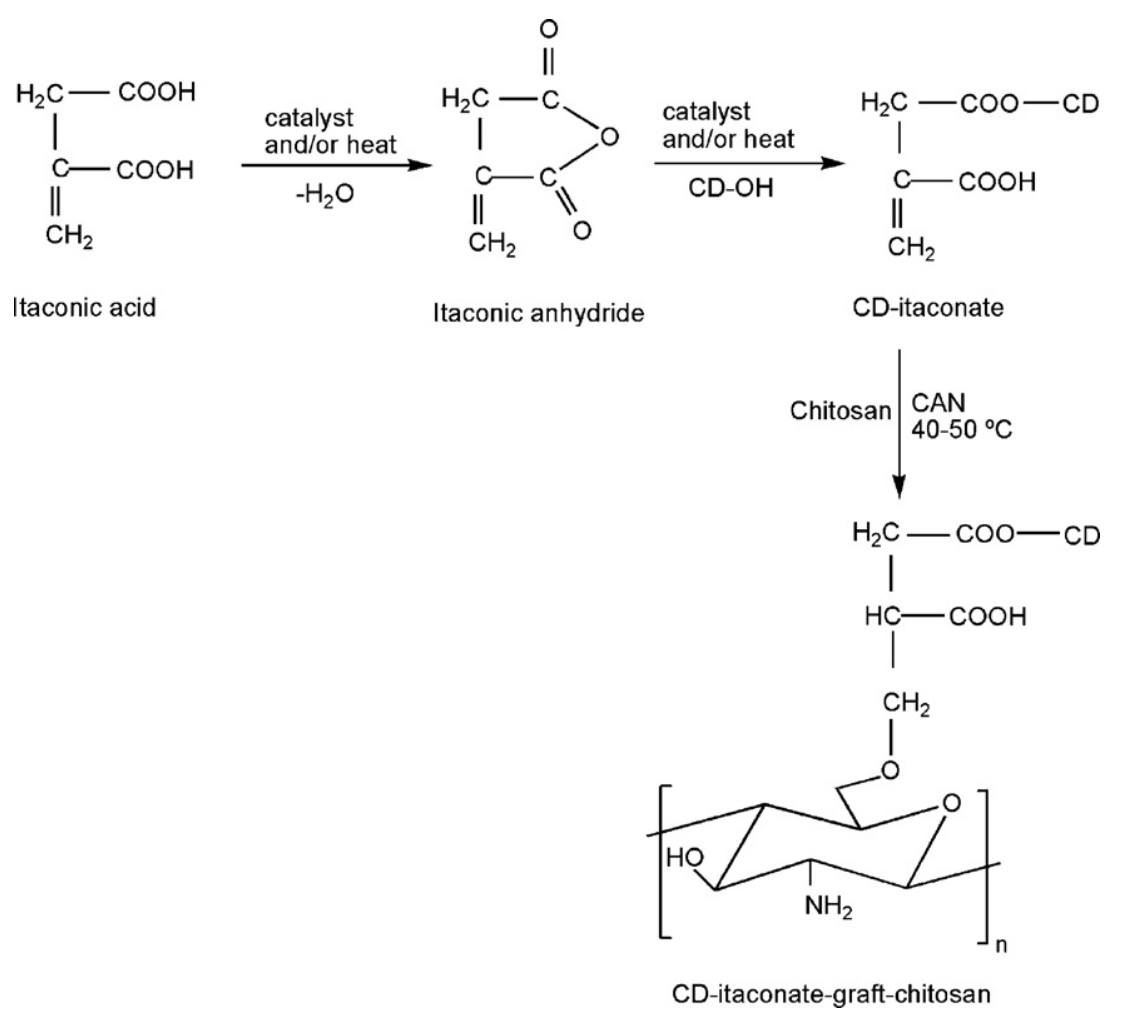

Fig. 8. Reaction scheme for the synthesis of CD itaconate-g-chitosan using CAN.

strates were synthesized by adding an aqueous acetic acid solution of chitosan into ethanolic aqueous sodium hydroxide and subsequent crosslinking with HMDI in DMF [75]. The resulting beads were further treated with $2-O$-formylmethyl- $\alpha-C D$ in the presence of sodium cyanoborohydride in acetate buffer at $\mathrm{pH} 4.4$, giving CDgrafted chitosan beads. In terms of $\mathrm{CD}$-inclusion complexes, the introduction of a guest molecule in the cavity classically takes place from the wider secondary hydroxyl groups side although the other situation may also be encountered, depending on the guest. It has been shown that the steric hindrance effects due to substitution of CDs could result in an important decrease of the association constant of complexes [76].

Recently, a new synthetic route was reported to graft $\beta-C D$ onto chitosan using an epoxy-activated chitosan [77]. Redox systems, such as CAN and potassium persulfate have also been used to graft $\mathrm{CD}$ onto chitosan. For example, $\beta$-CD-grafted chitosan was prepared by reacting $\beta-C D$ itaconate vinyl monomer with chitosan using CAN [78]. In this work, $\beta-C D$ itaconate was prepared by esterification of $\beta-C D$ with itaconic acid in a semidry process and then the pendent double bonds of $\beta-C D$ itaconate were utilized in the graft copolymerization onto chitosan (Fig. 8). The resultant product was then subjected to crosslinking using different concentrations of glutaraldehyde. This work showed that not only reactive sites play an important role in the sorption mechanism, but also other interactions, probably physical adsorption and hydrogen bond interactions, due to the crosslinking agent, and hydrophobic guest-guest interactions.

Due to the $C D$ moiety present in the chitosan backbone, it was found that $\beta$-CD-grafted chitosan has some selectivity for the adsorption of TNS, bisphenol A, p-nonylphenol, and cholesterol and has the stronger inclusion and slow release ability with iodine [72]. CD-grafted polymers form host-guest complexes with p-nitrophenol, p-nitrophenolate, tert-butylbenzoic acid, 6thiopurine, p-dihydroxybenzene, and copper ions [72].

\subsection{Thiol-containing chitosan}

Thiol-containing chitosan, also called thiolated chitosan, is obtained through the reaction between chitosan and thiolactic acid (Fig. 9). In this reaction, EDC can be used to graft these two materials [79]. EDC is a water-soluble carbodiimide that is typically employed in the 4.0-6.0 pH range. It is a zero-length crosslinking agent that has been widely used to couple carboxylic acid groups to primary amines. Thiolactic acid is covalently attached to the primary amino group of chitosan under the formation of amide bonds. The carboxylic acid moieties of thiolactic acid are activated by EDC forming a O-acylurea derivative as an intermediate product that reacts with the primary amino groups of chitosan. When compared with other

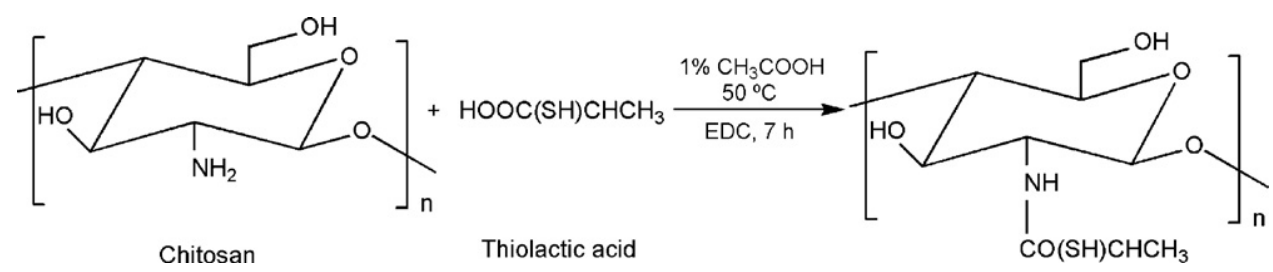

Fig. 9. Synthesis of thiol-containing chitosan. 


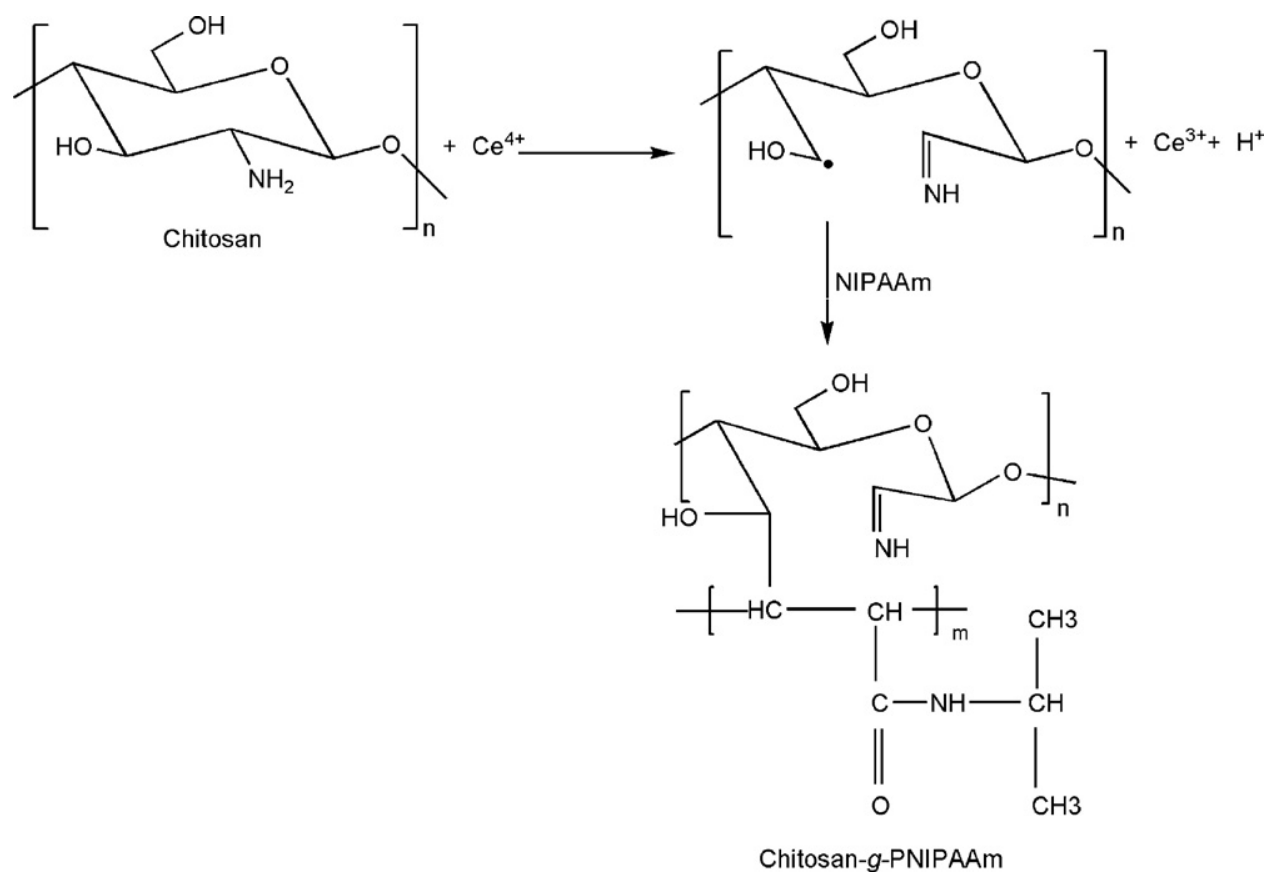

Fig. 10. Reaction scheme for the preparation of chitosan-g-PNIPAAm.

modified chitosan materials, thiolated chitosans have numerous advantageous features, such as significantly improved mucoadhesive and permeation enhancing properties [80-85]. Moreover, solutions of thiolated chitosans display in situ gelling properties at physiological $\mathrm{pH}$ values [82].

\section{4. "Smart chitosan": example of new chitosan-based hydrogels exhibiting temperature-responsive behaviour}

Smart hydrogels can undergo a reversible discontinuous volume phase change in response to various external physicochemical factors. Among them, temperature and $\mathrm{pH}$-responsive hydrogels have been the most widely studied, because these two factors can be applicable in vivo. Polymer solutions have a lower critical solution temperature (LCST) contract by heating above the LCST. These negative thermo-reversible hydrogels can be tuned to be liquid at room temperature and to undergo gelation when in contact with body fluids, due to an increase in temperature. Therefore, polymers having a LCST below human body temperature have a potential for injectable applications. Poly( $N$-isopropylacrylamide) (PNIPAAm) is a well known thermally reversible polymer, exhibiting a LCST around $32{ }^{\circ} \mathrm{C}$ in aqueous solution [86]. PNIPAAm hydrogels swell below the LCST and shrink above the LCST, when immersed in water.

Great attention has been paid, especially for biomedical applications, to the development of stimuli-responsive polymeric gels with unique properties such as biocompatibility, biodegradability and biological functionality. They may be prepared by combining thermo-responsive polymers such as PNIPAAm with natural based polymeric components, to form smart hydrogels [87-91]. Some polysaccharides, such as chitosan, alginate, cellulose and dextran, have been combined with thermo-responsive materials. Moreover, due to the $\mathrm{pH}$-sensitive character of chitosan, combination of this polymer with a thermo-responsive material will produce dualstimuli-responsive polymeric systems that can be used as delivery vehicles that respond to localized conditions of $\mathrm{pH}$ and temperature in the human body. A review on natural based stimuli-responsive polymeric gels has been recently published [92]. Next the two main chemical modifications used to prepare these smart hydrogels as well as some relevant examples are presented.

\subsection{Graft copolymerized hydrogels}

Hydrogels prepared by graft copolymerization of NIPAAm onto various types of polysaccharides have shown a LCST in the range of $25-34{ }^{\circ} \mathrm{C}$. Properties such as volume phase transfer and swelling character of the hydrogels, were found to be mainly dependent on their polymers weight ratio, crosslinking density and morphology. A number of initiator systems, such as CAN, APS, AIBN, 2,2'-azobis-(2-methylpropionamidine) dihydrochloride (AIBA), $N, N, N^{\prime}, N^{\prime}$-tetramethylethylene diamine (TEMED) and radiation techniques have been reported to graft NIPAAm onto chitosan. Fig. 10 shows the reaction that can be used to prepare chitosan- $g$ PNIPAAm using CAN [93].

Chitosan-g-PNIPAAm particles can also be synthesized by a soapless emulsion copolymerization method [94]. Either APS or AIBA may be used as initiators. In this case the swelling ratio of the copolymer decreased with increasing crosslinking density and $\mathrm{pH}$ value.

Graft copolymers based on a maleilated chitosan and NIPAAm have been synthesized by UV radiation. Maleilated chitosan was prepared by reacting chitosan with maleic anhydride [95]. The swelling ratio of maleilated chitosan-g-PNIPAAm depended on both $\mathrm{pH}$ and temperature of the aqueous solution.

Kim et al. synthesized hydrogels based on grafting chitosan with epoxy-terminated poly(dimethylsiloxane) (PDMS) also by using UV irradiation [96]. Hydrogels based on PNIPAAm-grafted chitosan were obtained but in this case by applying $\gamma$-irradiation [97]. The grafting percentage and the grafting efficiency increased with increasing the monomer concentration and the total irradiation dose. The swelling ratios of these chitosan-g-PNIPAAm hydrogels increased with the increase of the grafting percentage, which indicated that the swelling behaviour of the hydrogels depends on the amount of the grafted branches.

Graft copolymers can also be prepared by using the condensation reaction in the presence of EDC. Lee et al. synthesized 

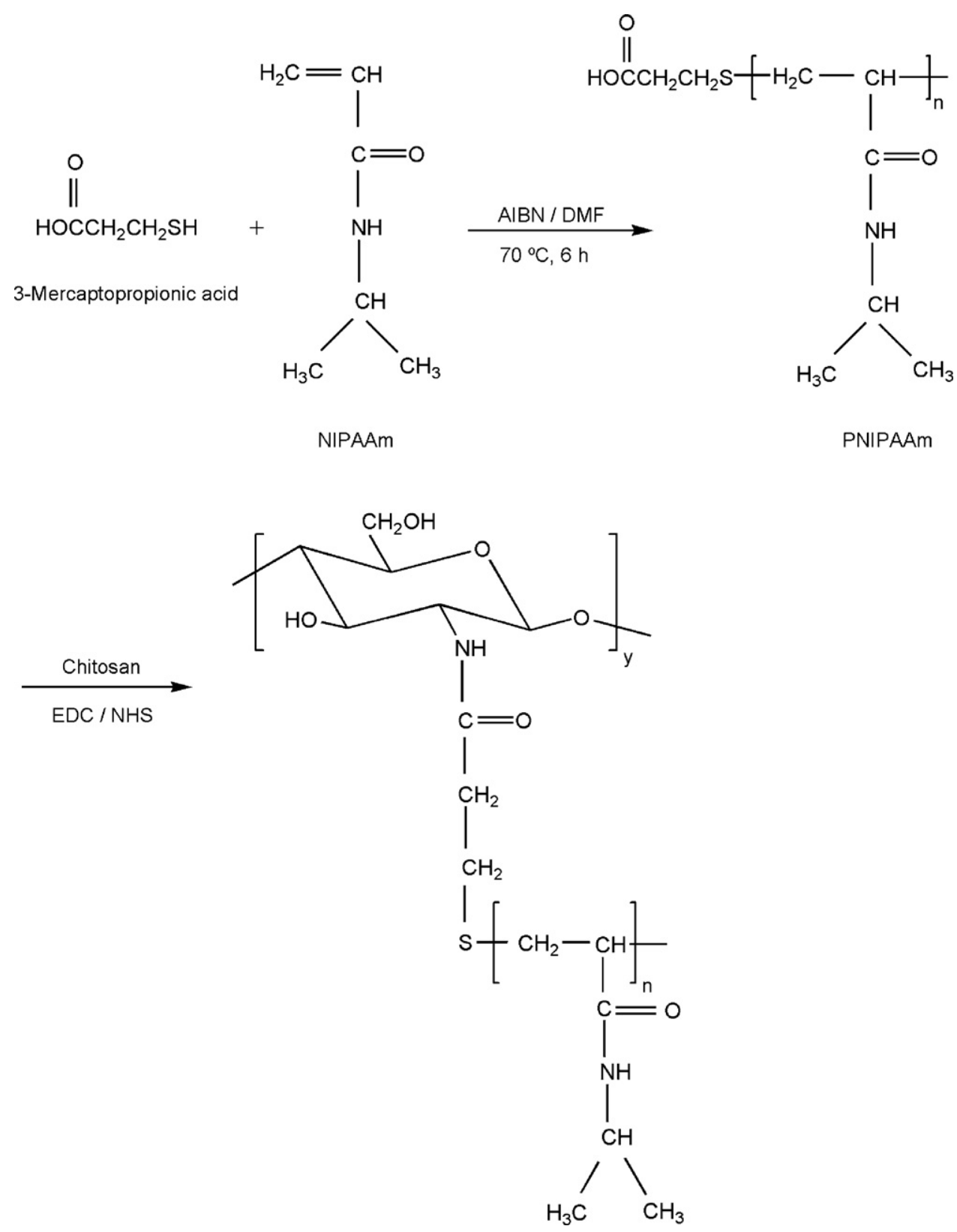

Fig. 11. Preparation of carboxyl-terminated PNIPAAm and comb-type graft hydrogel.

comb-type graft hydrogels, composed of chitosan and carboxylterminated PNIPAAm by using this carbodiimide [98]. EDC catalyzes the formation of amide bonds between the carboxylic acid groups of carboxyl-terminated PNIPAAm and the amine groups of chitosan. The reaction scheme for the preparation of carboxyl-terminated PNIPAAm, and its grafting onto chitosan is shown in Fig. 11. In the swelling/deswelling behaviour, comb-type graft hydrogels showed rapid temperature and $\mathrm{pH}$ sensitivity because of the free-ended PNIPAAm attached to the chitosan main chain and the chitosan amine group itself, respectively.

Recently, microgels with more complex structures, such as a multi-responsive core-shell, have received increasing attention because of the tunable properties of the individual responsive components. Various types of core-shell microgels have been prepared from the PNIPAAm-grafted polysaccharides. Leung et al.
$[99,100]$ developed smart microgels that consist of well-defined temperature-sensitive cores with $\mathrm{pH}$-sensitive shells based on PNIPAAm and chitosan. The properties of crosslinked poly(chitosanco-NIPAAm)/poly[methacrylic acid (MAA)-co-methyl methacrylic acid (MMA)] core-shell type copolymer particles were examined [101]. Here, the crosslinked copolymer of NIPAAm and chitosan was prepared as the core, and the copolymer of MAA and MMA was prepared as the shell.

Besides the many works that propose the association of PNIPAAm with chitosan, other few examples of distinct thermosensitive graft copolymerized hydrogels can be found. This is the case of those systems that combine amphiphilic block copolymers based on poly(ethylene oxide) (PEO) and poly(propylene oxide) (PPO), known as poloxamers, with chitosan. For instance, Creuzet et al. prepared this kind of hydrogels by grafting PEO-PPO blocks on chitosan [102]. 


\subsection{Chemically crosslinked blends}

Stimuli-responsive hydrogels can also be obtained by blending biopolymers with synthetic thermo-responsive materials by various mechanisms of chemical crosslinking. When we have an assembly of two crosslinked polymers and at least one of which is synthesized and crosslinked in the presence of the other, this system is called an interpenetrated network (IPN). If only one component of the assembly is crosslinked leaving the other in the linear form, the system is termed as semi-IPN. The ability to form a gel through the crosslinking of chitosan with PNIPAAm has been well documented. Many hydrogels are formed from watersoluble polymers by crosslinking them using crosslinking agents such as glutaraldehyde or polymerizing hydrophilic monomers in the presence of a crosslinker. Chemically crosslinked polymers seem to be one of the candidates to improve wet strength. Some works reporting the preparation of PNIPAAm-containing chitosan/glutaraldehyde gels can be found [103,104]. Another example is this kind of blends is glutaraldehyde crosslinked semi-IPNs of chitosan and PAN [105]. Of course, the water uptake of these systems increases as the molar ratio of the hydrophilic groups of chitosan increases. Khurma et al. reported the preparation of semi-IPNs based on chitosan and poly(vinyl pyrrolidone) (PVP) by using a natural crosslinking agent, genipin [106]. It was found that PVP-rich hydrogels swelled the most, because increasing the amounts of PVP makes the gel structure less compact, and more inhomogeneous.

A full-IPN hydrogel was synthesized by the chemical combination of a methylenebis(acrylamide) (MBAM) crosslinked PNIPAAm network with a formaldehyde crosslinked chitosan network [107]. The authors [107] demonstrated that the properties of the gels, including the extractability of PNIPAAm within it, the phase transition behaviour, the swelling dynamics in aqueous phase, the swelling behaviour in ethanol/water mixtures and even the microstructure were quite different from those of the corresponding semi-IPN hydrogels. It was found that the semi-IPN hydrogels swell faster than the corresponding full-IPN hydrogels, and that the swelling ratio for the semi-IPN hydrogels is almost independent of temperature [107].

\section{Applications for modified chitosan materials}

The potential applications of modified chitosan in various important fields, such as environment, drug delivery, tissue engineering and other biomedical application are here discussed. An attempt is also made to discuss some of the current applications and future prospects of modified chitosan.

\subsection{Drug delivery}

As said in Section 1, chitosan has interesting biopharmaceutical characteristics such as $\mathrm{pH}$ sensitivity, biocompatibility and low toxicity $[5,6]$. Moreover, chitosan is metabolised by certain human enzymes, especially lysozyme, and is biodegradable [5]. Due to these favorable properties, the interest in chitosan and its derivatives in drug delivery applications has been increased in recent years. Moreover, in such applications it is also extremely important that chitosan be hydro-soluble and positively charged. These properties enable it to interact with negatively charged polymers, macromolecules and polyanions in an aqueous environment.

Many works related with potential applications of chitosan and its derivatives can be found in literature. For instance, it has been shown that chitosan and its derivatives, such as $\mathrm{N}$ trimethyl chitosan or $\mathrm{N}$-carboxymethyl chitosan, have the special feature of adhering to mucosal surfaces, being useful for mucosal drug delivery $[10,108,109]$. Acrylic acid grafts of chitosan as possible means of creating hydrophilic and mucoadhesive polymers, have been reported recently [27,110]. Chitosan-grafted poly(acrylic acid) particles have been proposed as hydrophilic drug carriers for hydrophilic drugs and sensitive proteins [111]. Kumbar et al. prepared microspheres of polyacrylamide-grafted-chitosan crosslinked with glutaraldehyde to encapsulate indomethacin(IM), a nonsteroidal anti-inflammatory drug used in the treatment of arthrhitis [112]. Microspheres of grafted chitosan crosslinked with glutaraldehyde were prepared to encapsulate nifidifine (NFD), a calcium channel blocker and an antihypertensive drug. $N$-Lauryl carboxymethyl chitosan with both hydrophobic and hydrophilic groups was studied in connection with the delivery of taxol to cancerous tissues [113]. Other examples are related to the production of polymeric vesicles for encapsulation of hydrophobic compounds like bleomycin [114].

Some works related with intracellular delivery for gene therapy using modified chitosan-based materials were reported. In fact it has been argued that the most important application of alkylated chitosan is in DNA delivery such as proven with dodecyl chitosan [115]. The high transfection efficiency of alkylated chitosan was attributed to the increasing entry into cells facilitated by hydrophobic interactions and easier unpacking of DNA from alkylated chitosan carriers, due to the weakening of electrostatic attractions between DNA and alkylated chitosan.

In another work [116], deoxycholic acid, which is the main component of bile acids, was used to modify chitosan hydrophobically and to obtain self-assembling macromolecules for non-viral gene delivery system. The self-aggregate DNA complex from deoxycholic acid-modified chitosan was shown to enhance the transfection efficiency over monkey kidney cells [116]. The feasibility of these chitosan self-aggregates for the transfection of genetic material in mammalian cells was investigated. Self-aggregates can form charge complexes when mixed with plasmid DNA. These self-aggregate DNA complexes are considered to be useful for transfer of genes into mammalian cells in vitro and served as good delivery system composed of biodegradable polymeric materials. PEGylation of chitosan in order to increase its solubility, elongate the plasma circulation time and prolong the gene transfer has been another proposed technique for the sustained DNA release. For example, Zhang et al. [117] prepared chitosan-DNA complexes conjugated with alphamethoxy-omega-succinimidyl PEG, and the gene expression was improved in comparison with the chitosan-DNA complex both in vitro and in vivo. Microspheres physically combining PEG-graftedchitosan (PEG-g-CHI) with poly(lactide-co-glycolide) (PLGA) were formulated by Yun et al. [118]. They reported that these microspheres were capable of sustained release of PEG-g-CHI/DNA for at least 9 weeks, and the rate of DNA release was not modulated by varying the amount of PEG- $g$-CHI. In another work [119] folatePEG-grafted chitosan was synthesized and proposed for targeted plasmid DNA delivery to tumor cells. The authors found that folate conjugation in this system significantly improved gene transfection efficiency due to promoted uptake of folate receptor bearing tumor cells. In vitro and in vivo studies of gene transfection are being conducted in the laboratory to evaluate its gene transfection efficiency.

Very recently novel water-soluble nanoparticles that consist of a PAMAM dendrimer core with grafted carboxymethyl chitosan chains were successfully synthesized [120]. The non-cytotoxicity and successful internalization of these dendrimer nanoparticles by two different types of cells, i.e., cell lines and primary cultures, was demonstrated in this work. The authors also showed that the dexamethasone-loaded nanoparticles induced the osteogenic differentiation of rat bone marrow stem cells in vitro. So, these novel dendrimer nanoparticles may be used as targeted drug-delivery 
carriers to cover a wide range of applications that involve the efficient intracellular delivery of biological agents to modulate the behaviour of cells.

Thiol-containing chitosan beads were synthesized in order to be used as a controlled and pH-responsive drug delivery system [79]. It has been shown that P-chitosan beads have a great potential to be used as controlled drug release systems through oral administration since the release in the highly acidic gastric fluid region of the stomach is avoided [63,121].

Chitosan-based systems bearing $\beta$-cyclodextrin cavities have been proposed as a matrix for controlled release [122,123]. Due to the presence of the hydrophobic $\beta$-cyclodextrin rings, these systems provide a slower release of the entrapped hydrophobic drug.

Finally, stimuli-responsive hydrogels have shown an improved drug loading capacity, and a sustained release behaviour [92]. In particular, systems that combine chitosan and PNIPAAm have shown drug release profiles that can be controlled by both $\mathrm{pH}$ and temperature [124,125], constituting very promising materials. This kind of smart systems has also been proposed for gene delivery. For instance, Sun et al. [126] coupled a carboxyl-terminated NIPAAm/vinyl laurate (VL) copolymer with chitosan (PNVLCS) and examined the gene expression of PNVLCS/DNA complexes in C2C12 cells against temperature change. The results indicated that the transfection efficiency of PNVLCS/DNA complexes was improved by dissociation of the gene from the carrier by temporarily reducing the culture temperature to $20^{\circ} \mathrm{C}$. By contrast, naked DNA and lipofectamine did not demonstrate thermo-responsive gene transfection [126].

\subsection{Tissue engineering}

The present generation of tissue engineering (TE) research is based on the seeding of cells onto porous biodegradable polymer matrixes. A primary factor is the availability of good biomaterials to serve as the temporary matrix. Recently, chitosan and its derivatives have been reported as attractive candidates for scaffolding materials because they degrade as the new tissues are formed, eventually without inflammatory reactions or toxic degradation [116,127]. In TE applications the cationic nature of chitosan is primarily responsible for electrostatic interactions with anionic glycosaminoglycans, proteoglycans and other negatively charged molecules.

Some research works where the biological properties of chitosan and the mechanical properties of PLLA are combined have been reported. The in vitro fibroblast static cultivation on chitosangrafted PLLA films for 11 days showed that the cell growth rate on these films was faster than in chitosan and decreased when the feed ratio of PLLA to chitosan increases [128]. Surface functionalization of biodegradable PLLA was achieved by plasma coupling reaction of chitosan with PLLA [129]. The proliferation and morphology studies of two cell lines, L-929 (mouse fibroblasts) and L-02 (human hepatocytes), cultured on this surface showed that cells hardly spread and tended to become round, but could proliferate at almost the same speed as cells cultured on glass surface. This insight will help to clarify the mechanism of the switch between cell growth and differentiation. This grafted polymer can be used to control the morphology and function of cells, and hence has potential applications in tissue engineering.

Very recently novel PLLA-chitosan hybrid scaffolds were proposed as tissue engineering scaffolds and simultaneously drug release carriers [130]. In this innovative system a chitosan porous structure, in which cells and tissues would mostly interact, is created within the pore structure of a stiffer PLLA scaffold.

It has been shown that thiolated chitosan $[81,131]$ can provide an adequate scaffold structure: due to the in situ gelling properties it seems possible to provide a certain shape of the scaffold material by pouring a liquid thiolated chitosan cell suspension in a mold. Furthermore, liquid polymer cell suspensions may be applied by injection forming semi-solid scaffolds at the site of tissue damage. So they seem to be promising candidates for such applications.

Surfaces that can induce the formation of an apatite layer in vitro demonstrate improved bone-binding properties and calcium phosphate growth on P-chitin fibers and P-chitosan films has been reported after soaking with $\mathrm{Ca}(\mathrm{OH})_{2}[132,133]$. Water-soluble P-chitosans have been mixed with different calcium phosphate cements, showing an improvement in their properties [134,135], namely the mechanical strength, setting time, dissolubility of the start materials of the cements and they also bind calcium phosphate strongly afterwards. Moreover it has been shown that due to the smart nature of chitosan, the apatite formation of chitosangrafted PLLA films reinforced with Bioglass ${ }^{\circledR}$ can be controlled by $\mathrm{pH}$ [136], which could also have relevance in bone TE applications.

Another approach regarding the chemical modification of chitosan for TE applications has been to introduce the specific recognition of cells by sugars. A recent example of the synthesis of sugar-bound chitosan can be found in the work of Kim et al. [137]. They prepared mannosylated chitosan (MC) having the specific recognition to antigen presenting cells such as B-cells, dendritic cells and macrophages.

In addition to applications in controlled drug release, PNIPAAmgrafted chitosan-based materials have been exploited for controlling cell adhesion/detachment by changing the incubation temperature above or below its LCST $[138,139]$. Temperatureresponsive chitosan-graft-PNIPAAm [139] were applied for the culture of mesenchymal stem cells (MSCs). Chitosan-g-PNIPAAm copolymers with chondrogenic MSCs revealed the possibility of clinical applications, particularly as cell therapy technologies for treating vesicoureteral reflux [138].

\subsection{Antimicrobial agents and other biomedical applications}

Chitosan derivatives present interesting properties for woundhealing applications, because such materials can exhibit enhanced bacteriostatic activity with respect to pure chitosan. Ethylene diamine tetraacetic acid (EDTA) grafted onto chitosan increases the antibacterial activity of chitosan by complexing magnesium that under normal circumstances stabilizes the outer membrane of gram-negative bacteria [140]. The increase in chitosan antimicrobial activity is also observed with carboxymethyl chitosan, which makes essential transition metal ions unavailable for bacteria [141] or binds to the negatively charged bacterial surface to disturb the cell membrane [142]. Therefore, these materials are used in woundhealing systems, such as carboxymethyl chitosan for the reduction of periodontal pockets in dentistry [141] and chitosan-grafted with EDTA as a constituent of hydro-alcoholic gels for topical use [140]. Chitosan and chitooligosaccharide-grafted membranes showed antibacterial activity against Escherichia coli, Pseudomonas aeruginosa, methicilin-resistant Staphylococcus aureus (MRSA), and S. aureus [143]. Also, it was observed that the antimicrobial activity of chitosan and graft copolymers against Candida albicans, Trichophyton rubrum, and Trichophyton violaceum depends largely on the amount and type of grafted chains, as well as on the changes of $\mathrm{pH}[17]$.

It has been shown that chitosan derivatives have great potential to be used in other biomedical applications. As a result of the biocompatible properties such as good blood compatibility and cell growth efficiency, grafted chitosan materials have potential to be used in cardio-vascular applications [144,145]. It has been demonstrated that the permeability of chitosan membranes grafted with HEMA may be controlled through plasma-treatment having potential to be used in dialysis [146]. 


\subsection{Adsorption of metal ions}

The high sorption capacities of modified chitosan for metal ions can be of great use for the recovery of valuable metals or the treatment of contaminated effluents. A great number of chitosan derivatives have been obtained with the aim of adsorbing metal ions by including new functional groups onto the chitosan backbone. The new functional groups are incorporated into chitosan to increase the density of sorption sites, to change the $\mathrm{pH}$ range for metal sorption and to change the sorption sites in order to increase sorption selectivity for the target metal.

The grafting of carboxylic functions has frequently been regarded as an interesting process for increasing the sorption properties of chitosan. Usually, the aim of these modifications is to design chelating derivatives for the sorption of metal cations $[147,148]$. Another way to achieve the grafting of carbonyl and carboxylic functions may consist in reacting chitosan with carboxylic anhydrides [149].

The grafting of sulphur compounds on chitosan has been the subject of many studies for the design of chelating chitosan-based resins [150-152]. These sulphur derivatives have been successfully tested for the recovery of mercury and the uptake of precious metals, owing to the chelating affinity of sulphur compounds for metal ions. Sulphonic groups have been also grafted on chitosan to improve sorption capacity for metal ions in acidic solutions [153].

$\mathrm{N}$-Halochitosans prepared by reacting chitosan with sodium hypochlorite are good flocculants for metallic oxides along with many other contaminants [154]. $N$-Chloroacetyl chitosan, prepared by reacting chitosan with chloroacetic anhydride in chloroacetic acid exhibited high affinity for cations such as $\mathrm{Cu}^{2+}, \mathrm{Fe}^{3+}$ [155].

P-chitin and P-chitosan have a strong metal-binding ability. It was found that their adsorption of uranium is much greater than of the other heavy metal ions [52]. Also, the binding ability to alkaline earth metals was significantly enhanced by the introduction of phosphate groups [156]. In fact, Schwarzenbach et al. [157] considered that the phosphonic complexing agents were as effective or even more than those containing carboxylic groups.

The combination of CDs with chitosan for manufacturing new metal ion sorbents, typically by using a Schiff's base reaction, has also been adopted $[158,159]$. Other very recent approach involves the production and use of thiolated chitosan films for aqueous heavy metal ions detection, in particular for mercury [160]. The use of dendrimers combined with chitosan is currently under study for this kind of applications [161]. Qu et al. synthesized a series of chitosan derivatives by grafting ester- and amino-terminated dendrimer-like PAMAM into chitosan [161]. The results showed that these systems were completely insoluble in dilute acid solutions when the generations of grafted dendrimers were greater than or equal to 2 and that they exhibited excellent adsorption capabilities for $\mathrm{Au}^{3+}$ and $\mathrm{Hg}^{2+}$. Moreover the adsorption capabilities of aminoterminated products were higher than those of ester-terminated ones [161].

A great deal of attention has been paid to the grafting of crown ether on chitosan for manufacturing new metal ion sorbents using a Schiff's base reaction [162,163]. Aza crown ether-graft-chitosan and mesocyclic diamine-g-chitosan crown ether showed high selectivity for $\mathrm{Cu}^{2+}$ in presence of $\mathrm{Pb}^{2+}[164]$. The static adsorption properties of $\mathrm{Ag}^{+}, \mathrm{Cd}^{2+}, \mathrm{Pb}^{2+}$, and $\mathrm{Cr}^{3+}$ by chitosan hydroxyl aza crown ether (CTS-DA) and chitosan dihydroxyl mesocyclic diamine (CTDA) was reported [15,165]. So, it is expected that in a near future these new type chitosan crown ethers will have wide ranging applications for the separation and concentration of heavy metal ions in environmental analysis.

\subsection{Dye removal}

Chitosan, due to its high contents of amine and hydroxyl functional groups, has an extremely high affinity for many classes of dyes including disperse, direct, reactive, anionic, vat, sulphur and naphthol [166,167]. The only class for which chitosan has low affinity are cationic dyes [167,168]. To overcome this problem Crini et al. [169] recently suggested the use of $N$-benzyl mono- and disulfonate derivatives of chitosan in order to enhance its cationic dye hydrophobic adsorbent properties and to improve its selectivity. Carboxyl groups grafted onto chitosan may also serve as electron donors in an alkaline environment to confer chitosan the ability to adsorb cationic dyes from aqueous solutions. Modified chitosan gel beads with phenol derivatives were found to be effective in adsorption of cationic dyes, such as crystal violet (CV) and Bismarck brown $\mathrm{Y}(\mathrm{BB})[168]$.

Chitosan grafted with $C D$ s, in particular $\beta-C D$ derivatives, have ability to form complexes with a variety of other appropriate compounds, and are very promising materials for developing novel sorbent matrices $[16,170]$. Martel et al. showed that the adsorption of textile dyes from the effluent can be carried out with $\beta-C D-g$ chitosan derivatives [166]. Moreover, these systems have superior rate of sorption and global efficiency than that of parent chitosan polymer and of the well-known cyclodextrin-epichlorohydrin gels [166].

\section{Conclusions}

The different chemical modifications of chitosan developed by the extensive work of many researchers, summarized in this chapter, showed that it is possible to obtain chitosan derivatives not only soluble in acidic aqueous solutions but also in neutral and basic aqueous solutions. Moreover it has been demonstrated that these chitosan derivatives present the adequate properties for safe use in waste water treatments and, in particular, in biomedical applications such as controlled delivery of drugs or other bioactive agents and tissue engineering.

\section{References}

[1] K. Tomihata, Y. Ikada, Biomaterials 18 (1997) 567-575.

[2] Y.W. Cho, Y.N. Cho, S.H. Chung, G. Yoo, S.W. Ko, Biomaterials 20 (1999) 2139-2145

[3] R. Kumar, M.N.V. Muzzarelli, R.A.A. Muzzarelli, C.H. Sashiwa, A.J. Domb, Chem Rev. 104 (2004) 6017-6084.

[4] P.A. Sanford, in: G. Skjak-Braek, T. Anthonsen, P.A. Sanford (Eds.), Chitin and Chitosan-sources, Chemistry, Biochemistry, Physical Properties and Applications, Elsevier, London, 1989, pp. 51-70.

[5] R.A.A. Muzzarelli, Cell Mol. Life Sci. 53 (1997) 131-140.

[6] P.C. Bersch, B. Nies, A. Liebendorfer, J. Mater. Sci. Mater. Med. 6(1995) 231-240.

[7] K. Kurita, T. Kojima, T. Munakata, H. Akao, T. Mori, Y. Nishiyama, et al., Chem. Lett. 27 (1998) 317-318.

[8] H. Sashiwa, Y. Shigemasa, Carbohydr. Polym. 39 (1999) 127-138.

[9] A. Heras, N.M. Rodriguez, V.M. Ramos, Carbohydr. Polym. 44 (2001) 1-8.

[10] R. Jayakumar, R.L. Reis, J.F. Mano, Mater. Sci. Forum 514-516 (2006) 1015-1019.

[11] G. Lu, L. Kong, B. Sheng, G. Wang, Y. Gong, X. Zhang, Eur. Polym. J. 43 (2007) 3807-3818.

[12] R.A.A. Muzzarelli, M. Emmanueli, S. Mariotti, Carbohydr. Res. 107 (1982) 199-214.

[13] W.M. Xie, P.X. Xu, W. Wang, Q. Lu, Bioorg. Med. Chem. Lett. 11 (2001) 1699-1703.

[14] W.M. Xie, P.X. Xu, W. Wang, Q. Lu, Carbohydr. Polym. 50 (2002) 35-40.

[15] Z.K. Yang, Y. Yuan, J. Appl. Polym. Sci. 82 (2001) 1838-1843.

[16] S. Chen, Y. Wang, J. Polym. Sci. 82 (2001) 2414-2421.

[17] B.O. Jung, C.H. Kim, K.S. Choi, Y.M. Lee, J.J. Kim, J. Appl. Polym. Sci. 72 (1999) 1713-1719.

[18] M. Thanou, J.C. Verhoef, H.E. Junginger, Adv. Drug Deliv. Rev. 52 (2001) 117-126.

[19] A.S. Hoffman, G. Chen, X. Wu, Z. Ding, B. Kabra, K. Randeri, et al., Polym. Prepar. 38 (1997) 524-525.

[20] R.A. Tasker, B.J. Connell, S.J. Ross, C.M. Elson, Lab. Anim. 32 (1998) 270-275.

[21] K. Ono, Y. Saito, H. Yura, K. Ishikawa, J. Biomed. Mater. Res. 49 (2000) 289-295. 
[22] D.K. Singh, A.R. Ray, Carbohydr. Polym. 36 (1998) 251-255.

[23] T.M. Don, C.F. King, W.Y. Chiu, J. Appl. Polym. Sci. 86 (2002) 3057-3063.

[24] S.Y. Kim, S.M. Cho, Y.M. Lee, S.J. Kim, J. Appl. Polym. Sci. 78 (2000) 1381-1391

[25] M.Y. Pedram, J. Retuert, R. Quijada, Macromol. Chem. Phys. 201 (2000) 923-930.

[26] H.S. Blair, J. Guthrie, T.K. Law, P. Turkington, J. Appl. Polym. Sci. 33 (1987) 641-656.

[27] T. Sun, P. Xu, Q. Liu, J. Xue, W. Xie, Eur. Polym. J. 39 (2003) 189-192.

[28] T. Sun, W. Xie, P. Xu, Carbohydr. Polym. 58 (2004) 379-382.

[29] L.A. Berkovich, M.P. Tsyurupa, V.A. Davankov, J. Polym. Sci. Part A: Polym. Chem. Ed. 21 (1983) 1281-1287.

[30] M. Yalpani, R.H. Marchessault, F.G. Morin, C.J. Monasterious, Macromolecules 24 (1991) 6046-6049.

[31] J. Zhang, Y. Yuan, J. Shen, S. Lin, Eur. Polym. J. 39 (2003) 847-850.

[32] A. Pourjavadi, G.R. Mahdavina, M.J.Z. Mehr, H. Omidian, J. Appl. Polym. Sci. 88 (2003) 2048-2054.

[33] Y. Yilmaz, H. Caner, H. Hasipoglu, O. Yilmaz, Eur. Polym. J. 34 (1998) 493-497.

[34] K.E.L. Tahlawy, S.M. Hudson, J. Appl. Polym. Sci. 82 (2001) 683-702.

[35] Y. Liu, Z. Liu, Y. Zhang, K. Deng, J. Appl. Polym. Sci. 89 (2003) 2283-2289.

[36] A. Lagos, J. Reyes, J. Polym. Sci. Part A: Polym. Chem. Ed. 26 (1988) 985-991.

[37] L. Pengfei, Z. Maolin, W. Jilan, Radiat. Phys. Chem. 61 (2001) 149-153.

[38] Y. Shigeno, K. Kondo, K. Takemoto, J. Macromol. Sci. Pure Appl. Chem. A17 (1982) 571-583.

[39] D.K. Singh, A.R. Roy, J. Appl. Polym. Sci. 66 (1997) 869-877.

[40] L.L. Yu, Y. He, L. Bin, F. Yue, J. Appl. Polym. Sci. 90 (2003) 2855-2860.

[41] L.T. Ng, J.T. Guthrie, Y.J. Juan, H. Zhao, J. Appl. Polym. Sci. 79 (2001) 466-472.

[42] V. Singh, D.N. Tripathi, A. Tiwari, R. Sanghi, J. Appl. Polym. Sci. 95 (2005) $820-825$.

[43] J.S. Dordick, Trends Biotechnol. 10 (1992) 287-293.

[44] D.L. Kaplan, J.S. Dordick, R.A. Gross, G. Swift, in: R.A. Gross, D.L. Kaplan, G. Swift (Eds.), Proceedings of ACS Symposium Series, vol. 684, ACS, Washington, DC, 1998, pp. 2-16.

[45] G. Kumar, P.J. Smith, G.F. Payne, Biotechnol. Bioeng. 63 (1999) 154-165.

[46] K. Yamada, T. Chen, G. Kumar, O. Vesnovsky, L.T.D. Topoleski, G.F. Payne, Biomacromolecules (2000) 252-258.

[47] T. Chen, G. Kumar, M.T. Harris, P.J. Smith, G.F. Payne, Biotechnol. Bioeng. 70 (2000) 564-573.

[48] C. Muzzarelli, R.A.A. Muzzarelli, Trends Glycosci. Glycotechnol. 14 (2002) 223-229.

[49] S. Yoshikawa, T. Takayama, N. Tsubokawa, J. Appl. Polym. Sci. 68 (1998) 1883-1889.

[50] S.J. Hamodrakas, C.W. Jones, F.C. Kafatos, Biochim. Biophys. Acta 700 (1982) $42-51$.

[51] S.J. Hamodrakas, S.A. Asher, G.D. Mazur, J.C. Regier, K.C. Kafatos, Biochim. Biophys. Acta 703 (1982) 216-222.

[52] T. Sakaguchi, T. Hirokoshi, A. Nakajima, Agric. Biol. Chem. 45(1981)2191-2195.

[53] N. Nishi, S. Nishimura, A. Ebina, A. Tsutsumi, S. Tokura, Int. J. Biol. Macromol 6 (1984) 53-54.

[54] N. Nishi, A. Ebina, S. Nishimura, A. Tsutsumi, O. Hasegawa, S. Tokura, Int. J. Biol. Macromol. 8 (1986) 311-317.

[55] O. Somorin, N. Nishi, S. Tokura, J. Naguchi, Polym. J. 11 (1979) 391-395.

[56] K. Kaifu, N. Nishi, T. Komai, S. Tokura, O. Somorin, Polym. J. 13 (1981) 241-245.

[57] N. Nishi, H. Ohnuma, S. Nishimura, O. Somorin, S. Tokura, Polym. J. 14 (1982) 919-923.

[58] N. Nishi, J. Noguchi, S. Tokura, J. Noguchi, Polym. J. 11 (1979) 27-32.

[59] A. Heras, N.M. Rodriguez, V.M. Ramos, E. Agullo, Carbohydr. Polym. 44 (2001) $1-8$.

[60] J. Sludden, I.F. Uchegbu, A.G. Schätzlein, J. Pharm. Pharmacol. 52 (2000) 377-382.

[61] N.M. Ramos, N.M. Rodriguez, M.S. Rodriguez, A. Heras, E. Agullo, Carbohydr. Polym. 51 (2003) 425-429.

[62] V.M. Ramos, M.S. Rodríguez, E. Agulló, N.M. Rodríguez, A. Heras, Int. J. Polym. Mater. 51 (2002) 711-720.

[63] R. Jayakumar, R.L. Reis, J.F. Mano, J. Bioact. Compat. Polym. 21 (2006) 327-340.

[64] H.J. Buschmann, D. Knittel, E. Schollmeyer, J. Inclus. Phenom. Macrocycl. Chem. 40 (2001) 169-172.

[65] T. Loftsson, M.E. Brewster, J. Pharm. Sci. 85 (1996) 1017-1025.

[66] V. Laine, C.A. Sarguet, A. Gadelle, J. Defaye, B. Perly, D.F. Pilard, J. Chem. Soc., Perkin Trans. 2 (1995) 1479-1485.

[67] K. Uekama, J. Inclus. Phenom. Macrocycl. Chem. 44 (2002) 3-7.

[68] R.S.R. Pablo, J.R. Isasi, G.G. Gaitano, J. Photochem. Photobiol. A: Chem. 173 (2005) 248-257.

[69] S. Rozou, S. Michaleas, E.A. Vyza, J. Chromatogr. A 1087 (2005) 86-94.

[70] J. Szejtli, Cyclodextrin Technology, Kluwer Academic, London, 1988, p. 167.

[71] R. Auzely, M. Rinaudo, Macromol. Biosci. 3 (2003) 562-565.

[72] M. Prabaharan, J.F. Mano, Carbohydr. Polym. 63 (2006) 153-166.

[73] E. Furusaki, Y. Ueno, N. Sakairi, N. Nishi, S. Tokura, Carbohydr. Polym. 29(1996) 29-34.

[74] F. Tanida, T. Tojima, S.M. Han, N. Nishi, S. Tokura, N. Sakairi, et al., Polymer 39 (1998) 5261-5263.

[75] T. Tojima, H. Katsura, M. Nishiki, N. Nishi, S. Tokura, N. Sakairi, Carbohydr. Polym. 40 (1999) 17-22.

[76] V. Laine, V. Sarguet, C.A. Gadelle, A. Defaye, J.B. Perly, D.F. Pilard, J. Chem. Soc., Perkin Trans. 2 (1995) 1479.

[77] X. Zhang, Y. Wang, Y. Yi, J. Appl. Polym. Sci. 94 (2004) 860-864.
[78] M.A. Gaffar, S.M.E. Rafie, K.F.E. Tahlawy, Carbohydr. Polym. 56(2004)387-396.

[79] R. Jayakumar, R.L. Reis, J.F. Mano, Drug. Deliv. 14 (2007) 9-17.

[80] A.B. Schnurch, T.E. Hornof, Sci. Pharm. 69 (2001) 109-118.

[81] C.E. Kast, A.B. Schnurch, Biomaterials 22 (2001) 2345-2352.

[82] M. Hornof, C.E. Kast, A.B. Schnurch, Eur. J. Pharm. Biopharm. 55 (2003) 185-190.

[83] A.B. Schnurch, U.M. Brandt, A.E. Clausen, Sci. Pharm. 67 (1999) 196-208.

[84] A.B. Schnurch, M. Hornof, M. Zoidl, Int. J. Pharm. 260 (2003) 229-237.

[85] A.E. Clausen, C.E. Kast, A.B. Schnurch, Pharm. Res. 19 (2002) 602-608.

[86] H.G. Schild, Prog. Polym. Sci. 17 (1992) 163-249.

[87] G. Bokias, D. Hourdet, Polymer 42 (2001) 6329-6337.

[88] N. Kubota, N. Tasumoto, T. Sano, Y. Matsukawa, J. Appl. Polym. Sci. 80 (2001) $798-805$.

[89] A.M. Lowman, N.A. Peppas, J. Biomater. Sci. Polym. Ed. 10 (1999) 999-1009.

[90] J. Zhang, N.A. Peppas, J. Biomater. Sci. Polym. Ed. 13 (2002) 511-525.

[91] C. Peniche, W.A. Monal, N. Davidenko, R. Sastre, A. Gallardo, J. San Roman, Biomaterials 20 (1999) 1869-1878.

[92] M. Prabaharan, J.F. Mano, Macromol. Biosci. 6 (2006) 991-1008.

[93] J.W. Lee, M.C. Jung, H.D. Park, K.D. Park, G.W. Ryu, J. Biomater. Sci. Polym. Ed. 15 (2004) 1065-1079.

[94] C.F. Lee, C.J. Wen, C.L. Lin, W.Y. Chiu, J. Polym. Sci. Part A: Polym. Chem. 42 (2004) 3029-3037.

[95] T.M. Don, H.R. Chen, Carbohydr. Polym. 61 (2005) 334-347.

[96] I.Y. Kim, S.J. Kim, M.S. Shin, Y.M. Lee, D.I. Shin, S.I. Kim, J. Appl. Polym. Sci. 85 (2002) 2661-2666.

[97] H. Cai, Z.P. Zhang, P.C. Sun, B.L. He, X.X. Zhu, Radiat. Phys. Chem. 74 (2005) 26-30.

[98] S.B. Lee, D.I. Ha, S.K. Cho, S.J. Kim, Y.M. Lee, J. Appl. Polym. Sci. 92 (2004) 2612-2620.

[99] M.F. Leung, J. Zhu, F.W. Harris, P. Li, Macromol. Rapid Commun. 25 (2004) 1819-1823.

[100] M.F. Leung, J. Zhu, F.W. Harris, P. Li, Macromol. Symp. 226 (2005) 177-185.

[101] C.L. Lin, W.Y. Chiu, C.F. Lee, J. Colloid Interf. Sci. 290 (2005) 397-405.

[102] C. Creuzet, R. Auzély-Velty, M. Rinaudo, L'actualité chimique 294 (2006) 34-38.

[103] M. Wang, J. Qiang, Y. Fang, D. Hu, Y. Cui, X. Fu, J. Polym. Sci. Part A: Polym. Chem. 38 (1999) 474-481.

[104] F.M. Goycoolea, A. Heras, I. Aranaz, G. Galed, M.E. Fernandez-Valle, W.A. Monal, Macromol. Biosci. 3 (2003) 612-619.

[105] S.J. Kim, S.R. Shin, S.M. Lee, I.Y. Kim, S.I. Kim, J. Appl. Polym. Sci. 88 (88) (2003) 2721-2724.

[106] J.R. Khurma, D.R. Rohindra, A.V. Nand, Polym. Bull. 54 (2005) 195-204.

[107] M. Wang, Y. Fang, D. Hu, React. Funct. Polym. 48 (2001) 215-221.

[108] H.L. Lueben, B.J.D. Leeuw, B.W. Langemeyer, A.G.D. Boer, J.C. Verhoef, H.E. Junginger, Pharm. Res. 13 (1996) 1668-1672.

[109] M. Thanou, T. Nihot, M. Jansen, J.C. Verhoef, H.E. Junginger, J. Pharm. Sci. 90 (2001) 38-46

[110] H.Y. Jiang, X.Y. Ding, H. Ge, Y. Yuan, C. Yang, Biomaterials 23 (2002) 3193-3201.

[111] K.L. Shantha, U. Bala, K.P. Rao, Eur. Polym. J. 31 (1995) 377-382.

[112] S.G. Kumbar, K.S. Soppimath, T.M. Aminabhavi, J. Appl. Polym. Sci. 87 (2003) $1525-1536$.

[113] H. Yoshioka, K. Nonaka, K. Fukuda, S. Kazama, Biosci. Biotechnol. Biochem. 59 (1995) 1901-1904.

[114] A. Miwa, A. Ishibe, M. Nakano, T. Yamahira, S. Itai, S. Jinno, H. Kawahara, Pharm. Res. 15 (1998) 1844-1850.

[115] W.G. Liu, K.D. Yao, Q.G. Liu, J. Appl. Polym. Sci. 82 (2001) 3391-3395.

[116] Y.H. Kim, S.H. Kim, C.R. Park, Bioconj. Chem. 12 (2001) 932-938.

[117] Y. Zhang, J. Chen, Y. Zhang, Y. Pan, J. Zhao, L. Ren, et al., Biotechnol. Appl. Biochem. 46 (2007) 197-204.

[118] Y.H. Yun, H. Jiang, R. Chan, W. Chen, J. Biomater. Sci. Polym. Ed. 16 (2005) $1359-1378$.

[119] P. Chan, M. Kurisawa, J.E. Chung, Y.Y. Yang, Biomaterials 28 (2007) 540-549.

[120] J.M. Oliveira, N. Kotobuki, A.P. Marques, R.P. Pirraco, J. Benesch, M. Hirose, S.A. Costa, J.F. Mano, H. Ohgushi, R.L. Reis, Adv. Funct. Mater. 18 (2008) 1840-1853.

[121] P.P. Win, Y.S. Ya, K.J. Hong, T. Kajiuchi, Carbohydr. Polym. 53 (2003) 305-310.

[122] M. Prabaharan, J.F. Mano, Macromol. Biosci. 5 (2005) 965-973.

[123] A.H. Krauland, M.J. Alonso, Int. J. Pharm. 340 (2007) 134-142.

[124] C.A. Lorenzo, A. Concheiro, A.S. Dubovik, N.V. Grinberg, T.V. Burova, V.Y. Grinberg, J. Control. Rel. 102 (2005) 629-641.

[125] N. Bhattarai, H.R. Ramay, J. Gunn, F.A. Matsen, M. Zhang, J. Control. Rel. 103 (2005) 609-624.

[126] S.S. Sun, W. Liu, N. Cheng, B. Zhang, Z.Z. Cao, K.K. Yao, Bioconj. Chem. 16 (2005) 972-980.

[127] K. Tuzlakoglu, C.M. Alves, J.F. Mano, R.L. Reis, Macromol. Biosci. 4 (2004) 811-819.

[128] F. Yao, W. Chen, H. Wang, H. Liu, K. Yao, P. Sun, Polymer 44 (2003) 6435-6441.

[129] Z. Ding, J. Chen, S. Gao, J. Chang, J. Zhang, E.T. Kang, Biomaterials 25 (2004) 1059-1067.

[130] M. Prabaharan, M.A. Rodriguez-Perez, J.A. de Saja, J.F. Mano, J. Biomed. Mater Res. Part B: Appl. Biomater. 81B (2007) 427-434.

[131] E. Kast, W. Frick, U. Losert, A.B. Schnurch, Int. J. Pharm. 256 (2003) 183-189.

[132] M.R. Mucalo, Y. Yokogawa, M. Toriyama, T. Suzuki, Y. Kawamoto, F. Nagata, K. Nishizawa, J. Mater. Sci. Mater. Med. 6 (1995) 409-419.

[133] H.K. Varma, Y. Yokogawa, F. Espinosa, Y. Kawamoto, K. Nishizawa, F. Nagata, T. Kameyama, Biomaterials 20 (1999) 879-884. 
[134] X. Wang, J. Ma, Y. Wang, B. He, Biomaterials 22 (2001) 2247-2255.

[135] X. Wang, J. Ma, Y. Wang, B. He, Biomaterials 23 (2002) 4167-4176.

[136] C.I. Dias, J.F. Mano, N.M. Alves, J. Mater. Chem. 18 (2008) 2493-2499.

[137] T.H. Kim, J.W. Nah, M.H. Cho, T.G. Park, C.S. Cho, J. Nanosci. Nanotechnol. 6 (2006) 2796-2803.

[138] E.S. Gil, S.M. Hudson, Prog. Polym. Sci. 29 (2004) 1173-1222.

[139] J.H. Cho, S.H. Kim, K.D. Park, M.C. Jung, W.I. Yang, S.W. Han, Biomaterials 25 (2004) 5743-5751.

[140] C. Valanta, B. Christen, A. Bernkop-Schnurch, J. Pharm. Pharmacol. 50 (1998) $445-452$.

[141] R.A.A. Muzzarelli, G. Skjak-Braek, T. Anthonsen, P. Sandford, Appl. Polym. Sci. (1989) 87-99 (Elsevier, London).

[142] X.F. Liu, Y.L. Guan, D.Z. Yang, Z. Li, K.D. Yao, J. Appl. Polym. Sci. 79 (2001) 1324-1335.

[143] S.G. Hu, C.H. Jou, M.C. Yang, J. Appl. Polym. Sci. 88 (2003) 2797-2803.

[144] C. Mao, W.B. Zhao, A.P. Zhu, J. Shen, S.C. Lin, Process. Biochem. 39 (2004) 1151-1157.

[145] T.W. Chung, Y.F. Lu, S.S. Wang, Y.S. Lin, S.H. Chu, Biomaterials 23 (2002) 4803-4809.

[146] Y. Li, L. Liu, F. Fang, Polym. Int. 52 (2003) 285-290.

[147] R.A.A. Muzzarelli, F. Tanfani, M. Emanuelli, Biotechnol. Bioeng. 27 (1985) 1151-1157.

[148] I. Saucedo, E. Guibal, C. Roulph, P. Le Cloirec, Environ. Technol. 13 (1992) 1101-1116.

[149] Y. Shigemasa, H. Usui, M. Morimoto, H. Saimoto, Y. Okamoto, S. Minami, Carbohydr. Polym. 39 (1999) 237-243.

[150] E. Guibal, T. Vincent, R. Navarro Mendoza, J. Appl. Polym. Sci. 75 (2000) 119-134.

[151] G. Cardenas, P. Orlando, T. Edelio, Int. J. Biol. Macromol. 28 (2001) 167-174
[152] E. Guibal, N.V.O. Sweeney, T. Vincent, J.M. Tobin, React. Funct. Polym. 50(2002) 149-163.

[153] K. Kondo, S. Nakagawa, M. Matsumoto, T. Yamashita, I. Furukawa, J. Chem. Eng 30 (1997) 846-852.

[154] E.O. Dingilian, G.E. Heinsohn, PCT Int. Appl. 117 (1992) 153112 (WO 9208742 CA).

[155] T. Mori, C. Mori, Y. Nishiyama, K. Kurita, Kichin Kitosan Kenkyu 5 (1999) 168-169.

[156] N. Nishi, Y. Maekita, S. Nishimura, O. Hasegawa, S. Tokura, Int. J. Biol. Macromol 9 (1987) 109-114.

[157] G. Schwarzenbach, H. Ackermann, P. Ruckstuhl, Helv. Chim. Acta 32 (1949) 1175-1186.

[158] G. Paradossi, F. Cavalieri, V. Crescenzi, Carbohydr. Res. 300 (1997) 77-84

[159] G. Paradossi, E. Chiessi, F. Cavalieri, D. Moscone, V. Crescenzi, Polym. Gels Netw. 5 (1997) 525-540.

[160] M.D. Cathell, J.C. Szewczyk, F.A. Bui, C.A. Weber, J.D. Wolever, J. Kang, C.L. Schauer, Biomacromolecules 9 (2008) 289-295.

[161] R. Qu, C. Sun, C. Ji, C. Wang, H. Chen, Y. Niu, C. Liang, Q. Song, Carbohydr. Res. 343 (2008) 267-273.

[162] C. Peng, Y. Wang, Y. Tang, J. Appl. Polym. Sci. 70 (1998) 501-506.

[163] S. Tan, Y. Wang, C. Peng, Y. Tang, J. Appl. Polym. Sci. 71 (1999) 2069-2074.

[164] Z. Yang, Y. Wang, Y. Tang, J. Appl. Polym. Sci. 74 (1999) 3053-3058.

[165] Z. Yang, J. Li, J. Appl. Polym. Sci. 86 (2002) 2677-2681.

[166] B. Martel, M. Devassine, G. Crini, M. Weltrowski, M. Bourdonnaeu, M. Morcellet, J. Polym. Sci. Part A: Polym. Chem. Ed. 39 (2001) 169-176.

[167] G. Crini, P.M. Badot, Prog. Polym. Sci. 33 (2008) 399-447.

[168] A.C. Chao, S.S. Shyu, Y.C. Lin, F.L. Mi, Bioresour. Technol. 91 (2004) 157-162.

[169] G. Crini, B. Martel, G. Torri, Int. J. Environ. Pollut. 33 (2008).

[170] K. Sreenivasan, J. Appl. Polym. Sci. 69 (1998) 1051-1055. 